\title{
Die instelling van die doop
}

$J L$ Venter, Potchefstroom

Jan $J$ van der Walt, Potchefstroom

\section{ABSTRACT \\ The institution of baptism}

In the gospel, mention is made of baptism as a command of Jesus Christ, for the first time in Matthew $28: 16-20$. This is the place where the meaning of baptism becomes most evident, and where conversionist baptism is established. In Acts $2: 38,39$, Luke institutes the well-known infant baptism.

In the first pericope, it is clear that Jesus has the authority to give commands to his disciples. He confirms his authority over all nations by allowing them to be taught, and those who are prepared to follow Jesus Christ, and who react to the calling with faith, are baptized. Baptism occurs under the seal of the Holy Trinity, thereby depicting the protection of the Father, the atoning power of the Son, and the authentication thereof by the Holy Spirit. He guarantees his authority over the baptized of all generations with glorious promises.

Acts $2: 38,39$ illustrates the fact that children are just as inseparable a part of the covenant. In the terminology of the Old Testament regarding the covenant, it is presumed that when young children are present, they have also received the sign of baptism.

Die eerste plek in die evangeliebeskrywings waar daar van die doop as 'n opdrag van Jesus Christus gepraat word en waar die betekenis die duidelikste uitkristalliseer, staan in Matteus $28: 16-20$. Heilshistories gesien, is dit die begin van kerklike inlywing van die wat gehoor het hoedat Jesus sy koninkryk proklameer, die evangelie aanvaar en tot bekering kom. Vir die doel van hierdie artikel word hierdie gedeelte ondersoek om te sien hoe die instelling geskied het, wat die plek en betekenis van die Christelike doop is.

Daarna kom Handelinge $2: 38,39$ aan die orde om die vestiging en voortgang van die doop in die Nuwe-Testamentiese kerk te illustreer. Hierdie teksgedeelte handel oor die eerste sendingsituasie waar die instelling van die doop in praktyk gebring word. Hierdie werkswyse word hierna telkens in die Nuwe Testament herhaal.

\section{MATTEUS $28: 16-20$}

Die elf dissipels het die opstandingsboodskap van die vroue verneem en hulle na Galilea gehaas om hulle opgestane Here te ontmoet. Jesus Christus het geweet dat die stryd vir sy navolgelinge op aarde moeiliker 
sal raak hoe nader die eindes van die tye kom. Gevolglik gee Hy daar aan hulle as 't ware sy testament. Dit bestaan uit sekere waarborge en opdragte aan sy dissipels wat hulle deelname aan die vrug van sy versoeningswerk en die versekering van hul oorlewing bevestig.

Matteus het hierdie slotwoorde van Jesus Christus aan sy kerk struktureel so gerangskik dat die karakter, doel en betekenis van die doop duidelik na vore kom.

\subsection{Struktuurpatroon en uiteensetting van Jesus se woorde in Matteus $28: 18-20$}

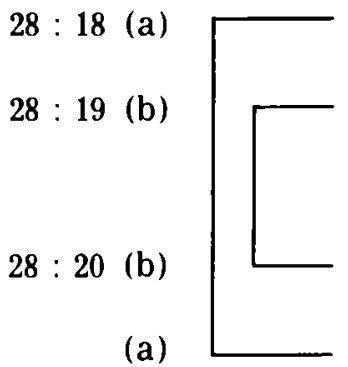

". . . Aan My is alle mag gegee in die hemel en op die aarde." (gesags-waarborg)

"Gaan dan na al die nasies toe en maak die mense my dissipels: doop hulle in die Naam van die Vader en die Seun en die Heilige Gees." (opdrag)

"Leer hulle om alles te onderhou wat Ek julle beveel het. (opdrag)

En onthou: Ek is by julle al die dae tot die voleinding van die wêreld." (gesags-waarborg)

Hierdie gedeelte word volgens 'n duidelike ringkomposisie van (a-b-ba) gestruktureer. Daarvolgens staan Jesus se opdrag (b-b), aan sy dissipels sentraal. Hierdie opdrag hou in dat hulle van die mense dissipels sal maak, hulle sal doop, en hulle sal onderrig om alles te onderhou wat Jesus hulle beveel het. Die opdrag aan sy dissipels word omring met die vaste waarborge dat $\mathrm{Hy}$ die gesag het om hulle te stuur en dat $\mathrm{Hy}$ hulle ewiglik sal bewaar.

\subsubsection{Die fundering van Jesus se gesag om opdragte te gee}

(Struktuurpatroon komponent (a) $28: 18$ )

Met hierdie woorde waarborg Jesus sy Goddelike gesag waarmee $\mathrm{Hy}$ van sy geboorte beklee is. Die Skrif gee nie 'n direkte roepingsbevel van die Vader tot sy Seun nie. Die doopgebeure (Matt $3: 16,17)$ kan wel as 'n "roepingsvisioen" gesien word (Hengel, 1981:63; Dunn, 1973/4:6; Hill, 1979:48). Tydens Jesus se doop dui die hemele wat oopgaan nie net op Jesus se ontvangs van die Heilige Gees nie, maar dit is die begin van die heilstyd wat aanbreek (Joel $2: 29$; Sag $12: 10$ ). Die pneumatologiese trekke rondom Jesus se doop dui op die Goddelike gesag en salwing waarmee Hy geroep is (Hill, 1979:49).

Met Johannes die Doper se gevangeneming het Jesus besef dat die ou bedeling verbygegaan het. Dit was vir Hom die teken dat Hy met sy proklamering van die koninkryk van God moes begin (Matt 4:12,17). Met Goddelike gesag in Homself sê Jesus anders as alle profete voor Hom: "Voorwaar Ek sê vir julle ..." (Matt $5: 18,20,26,28$ ).

Uit sy lewe is dit duidelik dat Jesus sy heerskappy oor hierdie wêreld 
en sy gesag oor alles, nie op 'n minderwaardige wyse bekom het nie. Toe die Satan Hom uitgelok het met die volle prys van wêreldheerskappy indien Jesus voor hom sou kniel, het Jesus hom met heilige afsku weggestuur. Hy kon die bose enduit weerstaan.

Jesus se prediking het die deurbraak van die koninkryk van God, en sy universele verlossing vir almal wat in Hom glo, bekend gemaak. Hy het sy woorde ook met kragtige historiese genesings as 'n werklikheid aan die volk bewys (vergelyk Matt $9: 31 ; 14: 14$ ).

\subsubsection{Sy gesag oor alle nasies bevestig met die doop}

(Struktuurpatroon komponent (b) $28: 19$ )

Jesus se koninkryksheerskappy moet oor al sy volgelinge uitgeoefen word, en hulle moet in gehoorsaamheid daarop antwoord. Hulle moet ook deur die eeue heen, ook wanneer Hy nie meer sigbaar onder sy volk teenwoordig is nie, bewus wees van sy verlossende genade en hul deelname aan sy oorwinning. Aangesien die volle deurbraak van sy koninkryk nog nie in hierdie bedeling sal geskied nie, moet die gelowiges op een of ander wyse daaraan herinner en daarvan verseker word dat hulle toekoms in Christus gewaarborg is.

Hierdie gesag van Jesus oor die wat in Hom glo, word bevestig met die doop.

Saam met die uitsendingsbevel om dissipels van die mense te maak, word 'n dubbele opdrag in een gegee, naamlik "om te doop en te onderrig". Die instelling van die doop gaan gepaard met die uitsendingsbevel om dissipels van die nasies te maak.

Matteus verbind die doop as opdrag spesifiek met die uitsending van die dissipels. Markus praat ook van die doop as 'n gevolg van die arbeid van die dissipels: ". . Gaan uit, die hele wêreld in, en verkondig die evangelie aan die hele mensdom. Wie tot geloof gekom het en gedoop is, sal gered word . . " (Mark $16: 15,16)$.

Lukas meld in $24: 47$ bloot ". . . en in sy Naam moet bekering en vergewing van sondes aan al die nasies verkondig word, van Jerusalem af en verder". Johannes meld in $20: 21$ bloot ". . . Soos die Vader My gestuur het, stuur Ek julle ook".

Die slotgedeelte van Matteus se beskrywing stel dit dus die duidelikste dat die doop as opdrag tuishoort by Jesus Christus se dissipels wat as gevolmagtigde ambassadeurs die evangelie oor die wêreld van hul tyd gaan verkondig. Hiermee word die doop binne die amptelike bediening van die dissipels geplaas. So verkry die doophandeling ' $n$ amptelike stempel binne die verbondskring waar geroepe en gesagvolle dienaars dit aan ander bedien.

Jesus het nie self gedoop nie, maar hierdie handeling aan sy dissipels toevertrou. "Die Fariseers het gehoor dat Jesus meer dissipels maak en doop as Johannes. Eintlik was dit nie Jesus wat gedoop het nie, maar sy dissipels" (Joh $4: 1,2)$. 


\subsubsection{Dissipels maak}

Die eerste opdrag volgens Matteus 28 : 19 is om van al die nasies dissipels te maak. Dit is 'n sendingopdrag. Die volkere moet leerlinge van Jesus word. Die nasies is nie veronderstel om net kennis van Jesus Christus te hê nie, maar hulle word ook geroep tot navolging. Om dissipels te maak, dui volgens die oorspronklike op 'n voortdurende proses wat nooit vir die dissipels tot 'n einde gaan kom nie.

\subsubsection{Doop}

Deur die dienswerk van sy ampsdraers word die nasies onderrig, en dié wat op die roeping met geloof en navolging reageer, word gedoop. Die doop wat hier benadruk word, is in die eerste plek die volwasse doop as 'n sigbare inlywing in die gemeenskap van gelowiges.

Dit is begryplik dat die instelling van die doophandeling 'n handeling tot volwasse mense sal wees. 'n Heel nuwe boodskap en die implikasies daarvan sal tog nie aan suigelinge oorgedra word nie, maar aan volwassenes wat eers die betekenis daarvan moet begryp. Dit was dus in die eerste plek ' $n$ bekeringsdoop. "Wie tot geloof gekom het en gedoop is, sal gered word; wie nie glo nie, sal veroordeel word" (Mark 16 : 16).

By die instelling van die doop is dit belangrik dat dit onder die versceling van die drie-enige God geskied. ". . En doop hulle in die Naam van die Vader en die Seun en die Heilige Gees." Met hierdie formule word die karakter van die doop bepaal. Die dopeling word so aan God toegewy, in en onder sy beheer geplaas dat die dopeling voortaan duidelik bewus is daarvan.

Hierdie drievoudige naamsaanduiding van God dui op Jesus se eie doop toe die volle Drie-eenheid in harmonieuse samewerking Jesus se werksaamhede op aarde bewillig het (Vader), bekragtig het (Heilige Gees), en aanvaar het (Jesus as Seun van God). Waar die doop onder die verseëling van die Naam van die drie-enige God geskied, dui die handeling daarop dat die dopeling deel het aan die beloftes en seeninge van die genadeverbond naamlik verlossing van sondes deur die versoeningswerk van Jesus Christus soos bewillig deur die Vader en bekragtig deur die Gees.

Hiermee word bevestig dat die dopeling onder die sorg van die hemelse Vader verseker word. Die Vader betuig met die doop dat Hy lewenslank Bondgenoot van die dopeling gaan wees. Die Vader sal sy verbond met die gelowige wat die teken en seell van die verbond dra, nie weer loslaat nie. Maar dan moet die gedoopte met sy lewe die betekenis van die doop bevestig en die waarheid daarvan uitleef.

Verder word die dopeling se lewe onder die versoenende krag van Jesus Christus ingedra sodat die dopeling ook verseker word van die nuwe lewe wat vir hom werklikheid word. Hierdie versekering word versterk deur die feit dat Jesus Christus self die dosp ingestel het as 'n uitwendige waterbad. "Of weet julle nie dat ons almal wat in Christus Jesus gedoop is, in sy dood gedoop is nie? Deur die doop is ons immers saam met Hom in sy dood begrawe, sodat, soos Christus deur die heerlike magsdaad

In die Skriflig $1989,23(2)-5$ 
van die Vader uit die dood opgewek is, ons ook so 'n nuwe lewe kan lei" (Rom $6: 3,4$ ).

Die doop wat as teken van God se verbond bedien word aan die wat glo, dit wil sê, besnede is van hart (Rom $2: 29$ ), beeld daarmee die afwassing van sonde uit. Dit word 'n seèl van die geregtigheid van die geloof (vergelyk Rom $4: 11$ ). Die geestelike gebeure van dit wat die doop uitbeeld, word deur die werklikheid van die uiterlike handeling ook 'n werklikheid.

Die uiterlike handeling van die doop het nie die vergewing van sondes tot gevolg nie, maar die vergewing van sondes lê veranker in die beloftes van God, wat net sigbaar tot versterking van die geloof met die doop beseël en bekragtig word.

Die instelling van die doop word so vir die gelowige ' $n$ blye geleentheid waaraan hy altyd weer vertroostend kan vasgryp; 'n fontein van heil waaruit hy altyd weer kan drink. Dit word deur die werking van die Heilige Gees in die gemoed van die gelowige gelē dat hy deur die Heilige Gees vernuut en geheilig word tot eiendom van Christus, sodat die gelowige al meer in sy lewe die sondes sal vełsaak en in ware toewyding tot God sal lewe.

Net soos wat Jesus Christus deur die dood heengegaan het en in 'n verheerlikte liggaam opgestaan het, so sal die dopeling ook deur die wederbarende en heiligende werking van die Heilige Gees vernuwe word. Die dopeling word met hierdie woorde in 'n nuwe intiem persoonlike verhouding met God gebring. Die doop dui in der waarheid daarop dat die gelowige saam met Hom begrawe is (Kol $2: 12$ ).

Verder dien die doop ook as 'n teken daarvan dat die gelowige nie meer op sy eie staan nie, maar dat hy in die verbondsgemeenskap van die kerk van Christus ingelyf word. In die Naam van die drie-enige God gedoop, word die dopeling as 'n volwaardige kind van die Here in sy huis en binne die gemeenskap van die gelowiges gereken.

\subsubsection{Sy gesag oor alle nasies versterk met onderrig}

(Struktuurpatroon komponent (b) $28: 20$ )

Hier kom die tweede deel van Jesus Christus se opdrag in Matteus 28 : 20 ter sprake naamlik: ". . . en leer hulle om alles te onderhou wat Ek julle beveel het ...". Eenmaal gedoop, sien op die eenmalige en voldoende afwassing van die sondes van my hele lewe, in so verre dit met 'n gelowige hart aanvaar en daarvolgens gelewe word. Die geloofsonderrig hou vir die volwasse gedoopte nie op na sy doop nie, en die gedoopte word nie vir die toekoms sonder verdere toerusting in die geloofswoestyn gelaat nie. Die gedoopte moet vir die res van sy lewe elke dag gehoorsaam hou by dit wat God in sy Woord beveel en met toewyding groei in dit waarin die Heilige Gees hom deur die Woord lei.

\subsubsection{Die gesag waarmee Jesus dit alles waarborg}

(Struktuurpatroon komponent (a) $28: 20$ )

Hierdie perikoop word begin met Jesus se fundering van sy gesag (Matt 
$28: 18)$ en nou word dit afgesluit met Jesus se ewige waarborg van daardie gesag. "En onthou: Ek is by julle al die dae tot die voleinding van die wêreld." (Matt $28: 20$.)

Hierdie woorde van die Here Jesus Christus dra die Nuwe Testamentiese kerk en beskerm haar sodat hierdie opdrag met sy beloftes vir alle geslagte deur al die komende eeue waar sal bly. Vanaf Pinkster word die doop met hierdie karakter, doel en betekenis in die Christelike Kerk bedien (vergelyk Petrus se optrede in Hand $2: 38$; Fillipus in Hand $8: 36-38$ ).

Wat ' $n$ troos is hierdie laaste woorde van Jesus Christus nie vir sy kerk nie! Dit is die kragtige waarborg dat sy genade en liefde nie net tot die twaalf beperk sou bly nie, maar vir die kerk van alle eeue, want die belofte strek hom uit tot aan die voleinding - tot die dag van die wederkoms van Jesus Christus (Floor, 1981: 108).

Die sekerheid, voortbestaan en oorlewing van die kerk van Jesus Christus hang nie in die eerste plek af van ons verhouding met God nie, maar alles draai om sy verhouding met ons en wat Hy ons skenk uit genade.

Hyself waarborg die beskerming van sy bruid hier op aarde deur die bediening van die versoening, die gawe van die geloof, die wekroep tot bekering en die heerlike versekering deur, in en met die doop. Hoe moeilik die pad van die toekoms vir elke gelowige ook al mag loop, kan hy altyd vasgryp aan sy doop as die teken en pand van God se ewige genadeverbond met die wat in Hom glo.

Die instelling van die doop is die goue draad van God se genadeverbond wat Hy met sorg deur die eeue inweef deur sy kerk tot en met die laaste dag, wanneer geloofsvertroue geloofsaanskoue sal word.

\section{HANDELINGE $2: 38,39$}

"Toe antwoord Petrus hulle: Bekeer julle en laat elkeen van julle gedoop word in die Naam van Jesus. Dan sal God julle sondes vergewe en sal julle die Heilige Gees as gawe ontvang. Wat God belowe het, is vir julle en vir julle kinders en vir almal wat daar ver is, vir almal wat die Here ons God na Hom toe sal roep."

Die praktyk van die doop was vir Petrus se gehoor nie vreemd nie. Net soos wat Johannes die Doper se hoorders beveel is om hulle te laat doop, met die doop as uiterlike teken van hul bekering, so moet Petrus se hoorders hulle ook laat doop. Vanselfsprekend preek Petrus vir en gee hy hierdie bevel aan volwassenes. Die verbondsteken word aan volwassenes bedien wat in die geloof op die verbondsluiting antwoord. Maar dit is duidelik dat die bevel en beloftes ook vir hulle kinders geld.

Die kinders van gelowige ouers is net so onlosmaaklik deel van die verbond. Hulle kan en mag nie van die teken van die verbond weggehou word asof hulle nie lidmate is van dic liggaam van Christus, naamlik sy kerk, nie. Net soos wat God sy verbond met Isak opgerig het voordat hy was, leer Petrus dat alle kinders van die gelowige Jode in dieselfde verbond inbegrepe is (Calvyn, 1970:95). 
Die beloftes van die verbond geld immers van die begin af vir Abraham en sy nageslag (vergelyk Gen $17: 7$; Deut $30: 6$; Ps $77: 9$; Jer $32: 39$ ). Daardie gelowige ouers wat van harte binne die raamwerk van die verbond lewe, kan nie anders as om hul kinders ook binne die verpligtinge en voorregte van die verbond groot te maak en toe te sien dat ook hulle kinders die verbondsteken ontvang nie.

Sowel die Ou-Testamentiese as die Nuwe-Testamentiese verbondsteken volg hierdie patroon van toesegging. Dit word bedien aan die volwassenes wat in die geloof op die verbondsluiting antwoord, en dit word voortgesit by die kinders wat deur die teken tot geloof geroep word (Smit, 1984:31) om die waarheid daarvan verder met hulle lewe te gaan bewys.

Voorbeelde uit die Skrif toon dat die kinderdoop in die vroee kerk nie 'n vreemde verskynsel was nie. Waar daar duidelike verbondsterminologie by die doop gebruik word in die Nuwe Testament dui dit daarop dat kindertjies by die doop ingesluit word (Konig, 1979:31). Wanneer daar gepraat word van "Lidia en haar huisgesin is toe gedoop" (Hand $16: 15$ ), sal geen Jood dit misverstaan nie. Daar hoef geen verdere bevel te wees om ook die kinders (een of ander tyd) te doop nie.

Die verbondsterminologie spreek die eenheid en saamgebondenheid van die ouers en kinders binne die verbond duidelik uit. Hierdie woorde impliseer dat as daar babatjies teenwoordig sou wees, hulle vanselfsprekend ook gedoop moet word (vergelyk Hand 10:24-28; Hand $16: 31-33 ; 1$ Kor $1: 16$ ). Sou die apostels bedoel het dat die kindertjies nie gedoop moet word nie, sou hulle as gevolg van die algemeen aanvaarde begrip van die Jode oor hierdie saak dit uitdruklik gesē het!

Die instelling van die doop as teken en seel van die verbond van God met die gelowiges en die praktyk van bediening soos wat dit in die Skrif vir groot en klein veronderstel word, bly 'n heerlike en troosryke gebeurtenis vir die kerk.

Met die doop bevestig God dat Hy sy handewerk deur die geslagte heen nooit sal laat vaar nie, maar volmaak gaan bevestig. Die instelling, plek en betekenis van die doop benadruk dit dat elke gedoopte erns sal maak met sy doop en die verpligtinge wat dit meebring nooit sal verontagsaam nie. Dan word die beloftes ook 'n ervaarde werklikheid!

Die belangrike plek wat die instelling van die doop in Matteus se slotwoorde ontvang en die duidelike beskrywing van die doop in Handelinge $2: 38,39$, verseker die gelowige daarvan dat hy nie alleen in die geloof deel het aan Jesus Christus se dood en opstanding nie, maar dat die gelowige so in die lewe van Christus ingelyf is dat hyself hier en nou deelgenoot word van al Christus se gawes.

Wat ' $n$ wonderlike vreugde is dit nie vir verbondsouers om dit ook van hul klein kindertjies se lewe in Christus te weet nie!

\section{BRONNELYS}

Calvyn. J. 1970. De Handelingen der Apostelen. Uit Latyn vertaal deur G. Wielinga Goudriaan: WA de Groot 
Dunn, JDG. 1973/4. New wine in old wine skins. The Expossitory Times, 85:4-7.

Floor, L. 1981. Uitgestuur. Die betroubare Woord. Skrifstudies oor Matteus 14-28. Johannesburg: Boekhandel de Jong.

Hengel. M. 1981. The charismatic leader and his followers. Vertaal deur Greig, JCG: Riches, J, red. Edinburgh: T \& T Clark

Hill. DH. 1979. New Testament prophecy. London: Marshall, Morgan \& Scott

Konig, A. 1979. Strydgesprek oor die kinderdoop. No. 1. Pretoria: NG Kerkboekhandel.

Smit. CJ. 1984. Die belang van die doop vir u kınd. Wat sê die Heilige Skrif? Pretoria: NG Kerkboekhandel. 